\title{
Avaliação da produtividade de variedades de milho safrinha consorciado com $U$. ruziziensis, em SPD visando produção de grãos e de forragem, na região da Nova Alta Paulista
}
Evaluation of winter maize yield varieties intercropped with U. ruziziensis, under no- tillage system for grain and forage production, in the Nova Alta Paulista region

Evaluación de la productividad de variedades de maíz de segunda cosecha consorciado con U. ruziziensis, en sistema de siembra directa con vistas a la producción de granos y de forraje, en la región de la Nueva Alta Paulista

Yanca Araujo Frias Mestranda do curso de Pós-graduação em Agronomia, FEIS UNESP, Brasil yanca_frias@hotmail.com

Ronaldo Cintra Lima Professor Assistente Doutor, FCAT UNESP - Dracena, Brasil. ronaldo.c.lima@unesp.br

Rafael Simões Tomaz Professor Assistente Doutor, FCAT UNESP - Dracena, Brasil. rafael.tomaz@unesp.br 


\title{
RESUMO
}

A cultura do milho (Zea mays) é um dos cereais mais expressivos da atualidade, ocupando a terceira colocação com aproximadamente 140 milhões de hectares semeados. A produção de milho no Brasil é caracterizada pela semeadura em duas épocas, primeira safra e segunda safra. A safrinha atualmente representa a época de maior produção de milho no Brasil, com a vantagem de ser um cultivo que se dá em sucessão à soja. Dessa forma, este trabalho visou investigar o desempenho de cinco variedades melhoradas de milho safrinha, semeados em SPD, sob resíduos de Urochloa ruziziensis cv. Ruziziensis e de soja, visando produção de grãos e silagem. Para instalação do experimento, foi considerado o delineamento de blocos casualizados, com seis repetições. Para cada variedade de milho, foram avaliadas as características: número de espigas (NE), altura de plantas (H), altura da primeira espiga (HPE), diâmetro de colmo (Dc), produtividade de massa seca de forragem (PMS) e produtividade de grãos (PG). O coeficiente de variação das características variou de médio, para NE, H, HPE, Dc e PG; e alto para PMS. As características NE, $\mathrm{H}$ e PMS obtiveram diferença significativa no teste estatístico de Scott-Knott $(p<0,05)$, já as demais características HPE, Dc e PG não apresentaram diferenças significativas. A variedade RIBER K 9105 destacou-se pelo seu maior rendimento na maioria das características agronômicas avaliadas, destacando-se para PMS.

PALAVRAS-CHAVE: Zea mays, sistema de plantio direto, produção

\begin{abstract}
Corn (Zea mays) is one of the most significant cereals today, occupying third place with approximately 140 million hectares planted. The production of corn in Brazil is characterized by sowing in two seasons, the summer maize crop and winter maize crop. Currently, the second maize crop, represents the greatest corn production in Brazil, with the advantage of being a crop that occurs in succession to soy. Thus, this work aimed to investigate the performance of five improved maize varieties, seeded in no-tilage system, under residues of Urochloa ruziziensis cv. Ruziziensis and soybean, aiming the production of grains and silage. For the installation of the experiment, it was considered a randomized complete block design, with six replications. For each maize variety, the following traits were evaluated: number of corn cob (NE), height of plants (H), height of first corn cob (HPE), diameter of stem (Dc), dry matter forage production (PMS) and yield production (PG). The traits coefficient of variation ranged from medium to NE, $H, H P E, D C$ and PG; and high for PMS. The characteristics NE, $\mathrm{H}$ and PMS obtained a significant difference in the Scott-Knott statistical test $(p<0.05)$, whereas the other HPE, Dc and PG characteristics did not show significant differences. The RIBER K 9105 variety was distinguished by its higher yield in the majority of evaluated agronomic characteristics, standing out for PMS.
\end{abstract}

Key words: Zea mays, no-tilage system, production.

\section{RESUMEN}

El cultivo del maíz (Zea mays) es uno de los cereales más expresivos de la actualidad, ocupando la tercera colocación con aproximadamente 140 millones de hectáreas sembradas. La producción de maíz en Brasil se caracteriza por la siembra en dos épocas, primera cosecha y segunda cosecha. Actualmente, la segunda cosecha representa la época de mayor producción de maíz en Brasil, con la ventaja de ser un cultivo que se da en sucesión a la soja. De esta forma, este trabajo tuvo como objetivo investigar el desempeño de cinco variedades mejoradas de maíz de segunda cosecha, en sistema de siembra directa bajo residuos de Urochloa ruziziensis cv. Ruziziensis y de soja, buscando producción de granos y forraje. Para la instalación del experimento, fue considerado el delineamiento de bloques casualizados, con seis repeticiones. Para cada variedad de maíz, se evaluaron las características: número de espigas (NE), altura de plantas $(\mathrm{H})$, altura de la primera espiga (HPE), diámetro de colmo (Dc), productividad de masa seca de forraje (PMS) productividad de granos (PG). El coeficiente de variación de las características ha variado de medio, para NE, H, HPE, Dc y PG; y alto para PMS. Las características NE, H y PMS obtuvieron una diferencia significativa por medio de la estadística de Scott-Knott $(p<0,05)$, ya que las demás características HPE, Dc y PG no presentaron diferencias significativas. La variedad RIBER K 9105 se destacó por su mayor rendimiento en la mayoría de las características agronómicas evaluadas, destacándose para PMS.

PALABRAS CLAVE: Zea mays, no-tilage system, production 


\section{INTRODUÇÃO}

A cultura do milho (Zea mays) é um dos cereais mais expressivos da atualidade, ocupando a terceira colocação com aproximadamente 140 milhões de hectares (FAGERIA et al. 2011). Isso devido ao uso desde alimentação humana e animal, estando inserido especialmente na cadeia produtiva de suínos e aves, os quais são responsáveis pelo consumo de aproximadamente $70 \%$ do milho produzido no mundo, e cerca de $70 \%$ e $80 \%$ do milho consumido no Brasil (EMBRAPA, 2006). De acordo com Veljković et al. (2018), o milho é uma cultura granífera com interessantes teores de óleo, sendo produzido globalmente para diversas destinações, como biodiesel. 0 Brasil possui uma produção de 85 milhões de toneladas e área plantada de 16,6 milhões de hectares, segundo dados da Companhia Nacional de Abastecimento (CONAB 2018).

A produção de milho no Brasil é caracterizada pela semeadura em duas épocas: primeira safra (ou safra de verão) e segunda safra (ou safrinha) (PEREIRA FILHO, 2015). A primeira safra ocorre em todos os estados nos meses com maior incidência pluviométrica. A safrinha refere-se ao cultivo do milho nos meses de janeiro a março ou até, no máximo, meados de abril, quase sempre depois da soja precoce e predominantemente na região Centro-Oeste e Sudeste (PEREIRA FILHO, 2015). Somente no estado de São Paulo, na safrinha de 2015/2016, foram plantados 384 mil hectares, tendo sido utilizados diversos cultivares de milho, os quais constituem uma boa alternativa de renda para pequenos e médios agricultores familiares.

Nos últimos anos, tem-se verificado decréscimo nas áreas plantadas da primeira safra, com produtividade compensada pelo aumento das áreas de semeadura no período da safrinha. Ainda, apesar das condições desfavoráveis de clima, os sistemas de produção da safrinha têm sido aprimorados e adaptados a tais condições, o que tem contribuído para elevar os rendimentos das lavouras também nessa época (PEREIRA FILHO, 2015).

A safrinha atualmente representa a época de maior produção de milho no Brasil, com a vantagem de ser um cultivo que se dá em sucessão à soja, aproveitando o efeito residual da adubação dessa cultura, o que contribui para sustentabilidade do sistema de produção (MARIZ et al., 2017). Em 2018, a produção do milho segunda safra foi de 58,2 milhões de toneladas, enquanto a produtividade do milho primeira safra foi de 26,8 milhões de toneladas (CONAB, 2018).

O Sistema Plantio Direto (SPD) é considerado um sistema conservacionista do solo, pois envolve um conjunto de técnicas integradas que visam aperfeiçoar a produção das culturas com diversas melhorias das condições ambientais possíveis.

Esse sistema, aliado ao uso de práticas conservacionistas complementares, como plantio em nível, terraceamento e adubação verde, tem forte influência sobre as condições físicas, químicas e biológicas do solo e no crescimento e desenvolvimento das plantas (ADAMS, 2016). Além de vantagens como controle da erosão, conservação da umidade, controle de plantas daninhas, e melhoria das condições fitossanitárias da cultura (BORTOLETI JR., 2015).

A produtividade do milho safrinha é influenciada principalmente pelas condições climáticas, que afeta o número de espigas por hectares, estande final de plantas, número de grãos por espiga e peso do grão (CONAB, 2018). A cultura do milho tem a vantagem de deixar grande quantidade 
de restos culturais que, uma vez bem manejados, podem contribuir para reduzir a erosão e proporcionar melhorias para as condições do solo.

Entretanto, são escassos na literatura informações a respeito de semeadura de variedades de milho safrinha sob SPD na região da Nova Alta Paulista, esta que é conhecida pela alta produtividade de cana-de-açúcar em plantio convencional.

Dessa forma, este trabalho visou investigar o desempenho de variedades melhoradas de milho safrinha, semeados em sistema plantio direto (SPD), sob resíduos de Urochloa ruziziensis $\mathrm{cv}$. Ruziziensis e de soja, visando produção de grãos e silagem.

\section{OBJETIVOS}

Avaliar o desempenho agronômico de cinco variedades de milho de segunda safra, em sistema plantio direto (SPD), semeadas sob resíduos de $U$. ruziziensis e de soja.

\section{MATERIAL E MÉTODOS}

\section{Características da área experimental}

O experimento foi conduzido na Área Experimental da Faculdade de Ciências Agrárias e Tecnológicas da UNESP - Câmpus de Dracena, coordenadas geográficas: Latitude $21^{\circ} 29^{\prime} \mathrm{S}$ e Longitude $51^{\circ} 52^{\prime} \mathrm{W}$, com altitude média de $420 \mathrm{~m}$.

O clima da região, segundo classificação de Köppen, é o subtropical úmido do tipo Cwa, com verão quente e chuvoso de outubro a março e inverno seco e ameno de baixa precipitação pluvial de abril a setembro. Apresentando médias anuais: temperatura $23,9^{\circ} \mathrm{C}$, umidade relativa $64,2 \%$, e precipitação pluvial de $1261 \mathrm{~mm} /$ ano. Os detalhes sobre os eventos climáticos durante o período experimental estão apresentados na Figura 1.

O solo na área do experimento foi classificado como Argissolo Vermelho-Amarelo Distrófico (SANTOS et al., 2018). Foi realizada amostragem de solo na profundidade de 0,0 a 0,20 m de forma a permitir os cálculos das adubações, baseadas na produtividade esperada do milho safrinha para produção de forragem de outono/inverno (RAIJ et al, 1996).

Tabela 1. Resultados da análise química do solo antes da semeadura.

\begin{tabular}{ccccccccccc}
\hline $\begin{array}{c}\text { Profundidade } \\
(\mathrm{cm})\end{array}$ & $\begin{array}{c}\text { P. resina } \\
\left(\mathrm{mg} / \mathrm{dm}^{3}\right)\end{array}$ & $\begin{array}{c}\mathrm{M} . \mathrm{O} . \\
\left(\mathrm{g} / \mathrm{dm}^{3}\right)\end{array}$ & $\mathrm{pH}$ & $\mathrm{K}$ & $\mathrm{Ca}$ & $\mathrm{Mg}$ & $\mathrm{H}+\mathrm{Al}$ & $\mathrm{Al}$ & $\mathrm{CTC}$ & $\mathrm{V}(\%)$ \\
\hline $0-20$ & 3 & 13 & 5.4 & 1,7 & 10 & 6 & 16 & 0 & 33,7 & 53 \\
\hline
\end{tabular}

Fonte: Laboratório de Fertilidade do solo da UNESP - Campus de Ilha Solteira. 
Figura 1: Comportamento climático: precipitação pluviométrica $(\mathrm{mm})$, evapotranspiração de referência $(\mathrm{mm})$ e temperatura média do $\operatorname{ar}\left({ }^{\circ} \mathrm{C}\right)$.

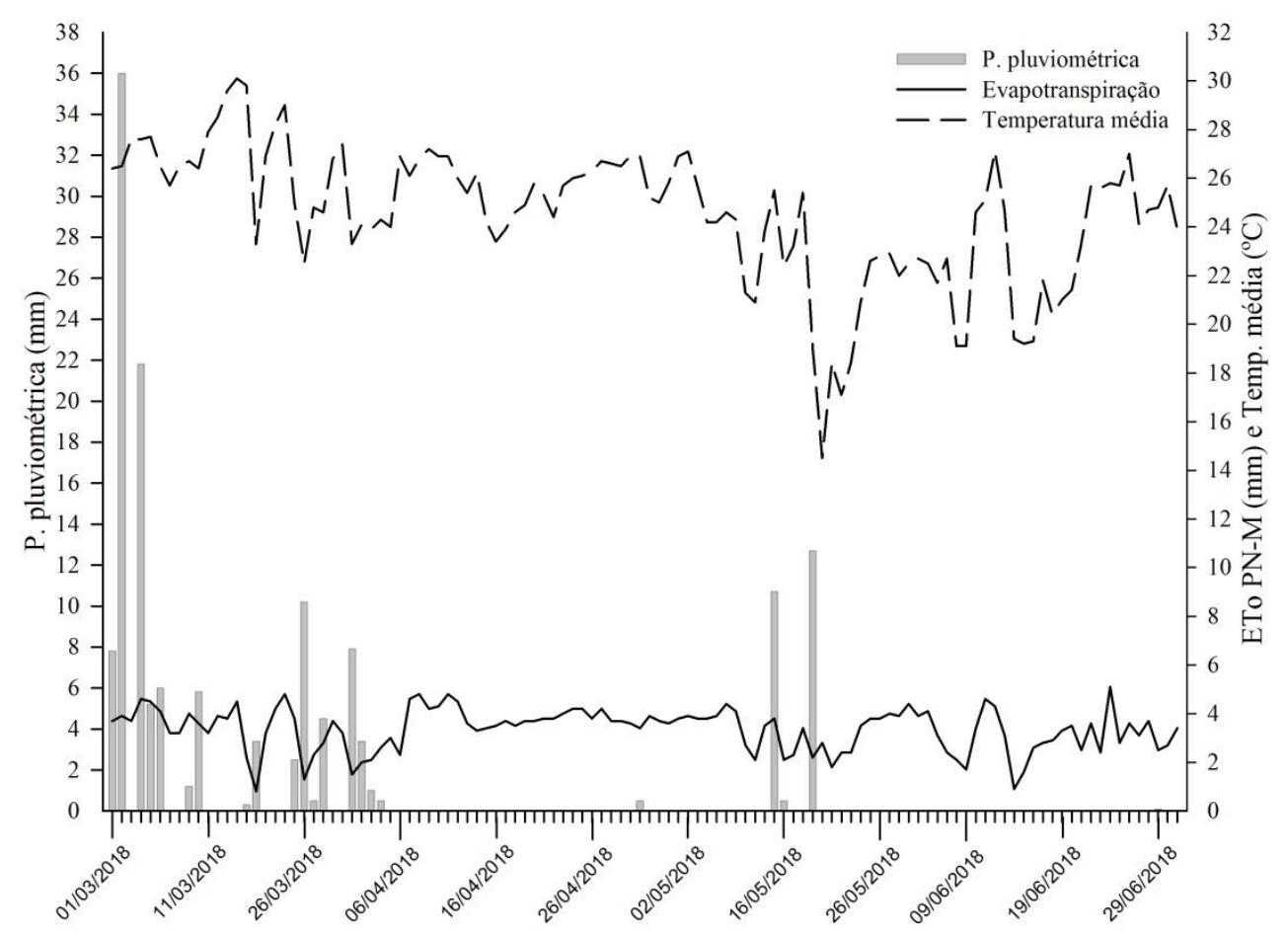

Fonte: Dados de pesquisa, 2019.

A área experimental foi explorada por pastagem em sistema extensivo por mais de 20 anos com forragem do gênero Urochloa brizantha. O presente sistema de produção teve início em abril de 2016 com a implantação Urochloa ruziziensis cv. Ruziziensis como cobertura vegetal para Sistema Plantio Direto das culturas vindouras. A implantação da cobertura visou fornecer sustentabilidade ao sistema, além de gradativamente, permitir a restauração do solo. Anteriormente à implantação do experimento, foi realizada correção do solo por meio de calagem baseando-se na análise química do solo, sendo este preparado por meio de uma aração profunda, com arado de discos e duas operações com grade niveladora, visando a incorporação do corretivo no solo para implantação do SPD. Em outubro do mesmo ano foi implantado o sistema safra/safrinha, iniciado com a soja de verão em sistema convencional e SPD, seguido das variedades do milho safrinha.

O experimento é parte integrante do projeto planejado para 4 anos de duração, iniciado em maio/2016 com término para abril/2020, composto por duas safras por ciclo: safrinha de milho consorciada com Urochloa ruziziensis cv. Ruziziensis, "planta formadora de palha para SPD", e safra de soja de verão, sob palha residual de milho e de U. ruziziensis oriunda do consórcio de milho safrinha. Os dados deste trabalho referem-se às variedades de milho safrinha semeadas em março de 2018. 


\section{Instalação e condução experimental}

O experimento foi conduzido em SPD com 5 híbridos de milho: AS 1777 PRO 3, RIBER RB 9006, RIBER K 9105, RIBER K 9606 VIP3 e DKB 177 PRO3, em consórcio com Urochloa ruziziensis cv. Ruziziensis, sob a massa seca das palhadas remanescentes de soja e de forrageira.

Para implantação da cultura do milho, foi realizada dessecação das plantas daninhas e remanescente da cultura (soja) antecessora em março de 2018. Foi utilizado o herbicida Roundup W.G. (glyphosate $720 \mathrm{~g} / \mathrm{kg}$ i.a.) na dose de $2,5 \mathrm{~kg} \mathrm{ha}^{-1}$ e volume de calda de $240 \mathrm{~L} \mathrm{ha}^{-1}$. Na sequência foi realizada a semeadura do consórcio entre a forrageira Urochloa ruziziensis $c v$. Ruziziensis e as variedades de milho safrinha com 60 mil plantas ha $^{-1}$ com adubação de base com $300 \mathrm{~kg} \mathrm{ha}^{-1}$ da fórmula 28-28-16, em SPD, implantados de forma simultânea, em março de 2018, ambas no espaçamento de $0,45 \mathrm{~m}$ entre linhas, sendo as plantas de cobertura instaladas nas entre linhas da cultura do milho, com 13,7 kg de sementes por hectare. Para implantação das culturas de milho e forrageiras foi utilizada a semeadora da marca GIHAL configurada para plantio direto, com 5 linhas e equipada com disco de corte de palha. As sementes das variedades de milho foram previamente tratadas com inseticida, fungicida, e nematicida microbiológico a base de Bacillus subtilis isolado UFPEDA 764 (mínimo de 3 x $109 \mathrm{ufc} / \mathrm{mL}$ ) na dosagem recomenda de $4 \mathrm{ml} \mathrm{kg}^{-1}$ de semente.

Foi realizada a segunda aplicação do nematicida microbiológico a base de Bacillus subtilis isolado UFPEDA 764 (mínimo de $3 \times 109 \mathrm{ufc} / \mathrm{mL}$ ) na dosagem recomenda de $8 \mathrm{~L} \mathrm{ha}{ }^{-1}$ em área total no estágio V2 de desenvolvimento das variedades de milho, para esta aplicação foi utilizado o trator/tanque pulverizador calibrado para o volume de calda de $240 \mathrm{~L} \mathrm{ha}^{-1}$.

Foram realizadas a adubação de cobertura com $120 \mathrm{~kg} \mathrm{ha}^{-1}$ nitrogênio na forma de ureia, e de $70 \mathrm{~kg} \mathrm{ha}^{-1} \mathrm{~K}_{2} \mathrm{O}$ na forma de cloreto de potássio. Os valores das adubações de cobertura foram parcelados em duas vezes de iguais valores, aos 20 e 50 dias após a germinação.

Para o controle de pragas (Lagarta-do-cartucho e Percevejo-barriga-verde) foram utilizadas três aplicações, sendo duas aplicações com o produto Engeo Pleno S (tiametoxan $141 \mathrm{~g} / \mathrm{L} \mathrm{14,1 \%} \mathrm{m/v}$ de i.a.) na dose de $200 \mathrm{~mL} \mathrm{ha}^{-1}$ e uma com Connect SC (imidacloprido $100 \mathrm{~g} / \mathrm{L} \mathrm{10,0 \%} \mathrm{m/v} \mathrm{de} \mathrm{i.a.)}$ na dose de $800 \mathrm{~mL} \mathrm{ha}^{-1}$. Para controle de doença "ferrugem" foi utilizado o produto Elatus WG (azoxistrobina) $300 \mathrm{~g} / \mathrm{kg}\left(30 \% \mathrm{~m} / \mathrm{m}\right.$ de i.a.) na dose de $800 \mathrm{~mL} \mathrm{ha}^{-1}$. Todas as aplicações dos produtos citados acima foram aplicadas com o trator/tanque pulverizador, calibrado para volume de calda de $240 \mathrm{~L} \mathrm{ha}^{-1}$.

O manejo da irrigação foi baseado na evapotranspiração de referência (ETo) obtidas a partir da Estação Meteorológica Campbell Scientific CR10X, instalada na FCAT, estimada pelo método de Penman-Monteith (ALLEN et al., 1998) e corrigido pelo coeficiente da cultura (Kc) das respectivas fases fenológicas da cultura. Foi utilizado o sistema de irrigação por aspersão convencional, composto de 2 linhas com 6 aspersores da marca Fabrimar espaçados 12x12 m entre os aspersores e as linhas respectivamente, com lâmina bruta de $5,4 \mathrm{~mm} \mathrm{~h}^{-1}$, pressão de serviço (PS) de $2,0 \mathrm{kgf} / \mathrm{cm}^{2}$ e turno de rega de 4 dias.

A colheita do milho do experimento e determinação dos caracteres agronômicos foi realizada em junho de 2018, quando os grãos das espigas se apresentavam no estágio de $3 / 4$ da linha do 
leite para a produtividade de forragem e para a produtividade de grãos após a maturação fisiológica do mesmo.

\section{Delineamento experimental e variáveis analisadas}

Para instalação do experimento, foi considerado o delineamento de blocos casualizados, com seis repetições, tomando como unidade experimental cinco linhas de oito metros de comprimento com espaçamento de $0,45 \mathrm{~m}$, das quais foram avaliadas as três linhas centrais (três metros centrais).

Para cada variedade de milho, foram avaliadas as características: número de espigas (NE), altura de plantas $(\mathrm{H})$, altura da primeira espiga (HPE), diâmetro de colmo (Dc), produtividade de massa seca de forragem (PMS) e produtividade de grãos (PG). As medidas de H, HPE e D foram realizadas em dez plantas por parcela tomadas aleatoriamente. As medidas foram realizadas com o auxílio de uma régua graduada em centímetros e paquímetro graduado em milímetros. O diâmetro do colmo foi medido na altura do primeiro entrenó acima do solo.

Para a determinação da produção de massa seca de forragem da planta inteira (colmos + folhas + espigas) foram colhidas e pesadas as plantas de três linhas centrais de $3 \mathrm{~m}$ em cada parcela, colhidas a 0,5 $\mathrm{m}$ de altura em relação ao nível do solo. A determinação da massa seca de forragem foi realizada a partir de uma amostra de cada parcela, onde foram tomadas três plantas, as mesmas foram picadas e acondicionada em sacos de papel, e em seguida as amostras foram secas em estufa a $65^{\circ} \mathrm{C}$ por 72 horas até atingir peso constante, para a determinação da massa seca (MS) de forragem. Para o cálculo da produtividade de MS de forragem com grãos, os valores foram extrapolados para quilograma de MS de forragem por hectare. Para produtividade de grãos foram coletadas as espigas nas mesmas dimensões igualmente utilizadas para a determinação da produtividade da massa seca de forragem, em seguida as mesmas foram secas naturalmente e trilhadas, pesadas, efetuada a umidade em estufa a $65^{\circ} \mathrm{C}$ por 72 horas até atingir peso constante, e em na sequência a produtividade foi corrigida a $13 \%$ a base úmida (13\%ви).

\section{Análise estatística dos dados}

Para análise dos variáveis consideradas, foi realizada análise de variância considerando o modelo estatístico: $Y_{i j}=m+T_{i}+B_{j}+e_{i j}$. Em que: $Y_{i j}$ corresponde ao valor observado para a variável em estudo referente ao tratamento $i$ no bloco $j ; m$, corresponde à média de todas as unidades experimentais para a variável em estudo; $T_{i}$, ao efeito do particular tratamento $i$ no valor observado $Y_{i j} ; B_{j}$, ao efeito do bloco $j$ no valor observado $Y_{i j}$; e $e_{i j}$, ao erro experimental na observação $Y_{i j}$.

Foi estimado o desempenho produtivo das variedades as quais potencialmente poderiam ser recomendadas para o cultivo, em SPD, na região da Nova Alta Paulista. As características que apresentaram significância na ANOVA foram submetidas ao teste de Scott-Knott $(p<0,05)$ para 
comparação de médias. Toda a análise estatística foi realizada por meio de rotinas a serem desenvolvidas no Software livre R (R Core Team, 2019).

\section{RESULTADOS}

$\mathrm{Na}$ Tabela 2 estão apresentados os resultados da análise de variância para as características avaliadas. Foi detectada significância para as características NE, H e PMS. O resultado do teste de Scott-Knott $(p<0,05)$ para comparação de médias das variedades, para essas características, está apresentado na Tabela 3.

Tabela 2: Resultado da análise de variância para as características avaliadas: número de espigas (NE), altura de plantas $(\mathrm{H})$, altura da primeira espiga (HPE), diâmetro do colmo (Dc), produtividade de massa seca de forragem (PMS) e produtividade de grãos (PG).

\begin{tabular}{cccccccc}
\hline \multirow{2}{*}{$\mathrm{FV}$} & \multirow{2}{*}{$\mathrm{gl}$} & \multicolumn{6}{c}{$\mathrm{QM}$} \\
\cline { 2 - 8 } & & $\mathrm{NE}$ & $\mathrm{H}$ & $\mathrm{HPE}$ & $\mathrm{Dc}$ & $\mathrm{PMS}$ & $\mathrm{PG}$ \\
\hline Tratamento & 4 & $1594065945^{*}$ & 868,55 & $123,87^{\text {ns }}$ & $10,46^{\text {ns }}$ & $9288573^{*}$ & $1267547^{\text {ns }}$ \\
Bloco & 5 & $340639130^{\text {ns }}$ & 112,23 & $16,21^{\text {ns }}$ & $8,15^{\text {ns }}$ & $3066369^{\text {ns }}$ & $240038^{\text {ns }}$ \\
Resíduo & 20 & 171355992 & 308,29 & 72,921 & 7,84 & 2153422 & 566852 \\
\hline CV (\%) & 14,63 & 10,13 & 10,48 & 16,23 & 23,90 & 12,34 \\
$\bar{x}$ & & 89465,02 & 173,32 & 81,20 & 17,24 & 6139,55 & 6101,80 \\
\hline
\end{tabular}

CV (\%): Coeficiente de Variação. ${ }^{*}$ - $p<0,05 ;{ }^{* *}-p<0,01 ;{ }^{\text {ns }}$ - não significativo. Fonte: Dados de pesquisa, 2019.

O coeficiente de variação das características variou de médio, para NE, H, HPE, Dc e PG; e alto para PMS. De acordo com Pimentel Gomes (1990), o coeficiente de variação (CV) permite a avaliação da precisão dos experimentos agrícolas, sendo considerado baixo quando inferior a $10 \%$; médio, quando entre 10 e $20 \%$; alto, quando entre 20 e $30 \%$; e muito alto, quando superior a $30 \%$. A classificação do CV é inversamente proporcional à classificação da precisão do experimento, de forma que quanto maior o CV, menor a precisão experimental. Coeficiente de variação baixo denota alta precisão; CV médio, média precisão; CV alto, baixa precisão; e CV muito alto, muito baixa precisão experimental.

Em observação a classificação de Pimentel Gomes (1990), o presente trabalho apresentou valores médios (quando entre 10 e 20\%) para todas as variáveis analisadas, visto na Tabela 2, deferindo dos valores de pesquisa apresentados por Kappes (2010), que avaliou variáveis semelhantes para diferentes híbridos, onde obteve em seus dados, coeficientes de variação considerados baixos $(<10 \%)$ para todas as variáveis.

As características NE, $\mathrm{H}$ e PMS obtiveram diferença significativa a $5 \%$, já as demais características HPE, Dc e PG não apresentaram diferenças significativas. 
Tabela 3: Teste de comparação de médias das características agronômicas de milho safrinha em consórcio com Urochloa ruziziensis cv. Ruziziensis, semeadas em SPD sob cobertura vegetal. Tratamentos seguidos pela mesma letra não diferem entre si pelo teste de Scott-Knott $(p<0,05)$.

\begin{tabular}{lcccccc}
\hline \multirow{2}{*}{ Variedade } & \multicolumn{7}{c}{ Médias } \\
\cline { 2 - 7 } & NE & H & HPE & Dc & PMS & PG \\
\hline AS 1777 PRO3 & $78189 \mathrm{~b}$ & $155 \mathrm{~b}$ & 76 & 16,61 & $4384 \mathrm{~b}$ & 5574 \\
RIBER RB 9006 & $77366 \mathrm{~b}$ & $175 \mathrm{a}$ & 86 & 15,71 & $5898 \mathrm{~b}$ & 6023 \\
RIBER K 9105 & $117284 \mathrm{a}$ & $185 \mathrm{a}$ & 83 & 17,58 & $7602 \mathrm{a}$ & 6571 \\
RIBER K 9606 VIP3 & $88888 \mathrm{~b}$ & $182 \mathrm{a}$ & 84 & 19,26 & $7028 \mathrm{a}$ & 6577 \\
DKB 177 PRO3 & $85596 \mathrm{~b}$ & $167 \mathrm{~b}$ & 77 & 17,09 & $5787 \mathrm{~b}$ & 5764 \\
\hline
\end{tabular}

Fonte: Dados de pesquisa, 2019.

A característica NE, associada ao estande, está normalmente associada à produtividade da cultura. Para essa característica, a variedade RIBER K 9105 apresentou maior média, sendo significativamente diferente das demais. De acordo com Freitas (1990) a quantidade de espigas está associada diretamente com a qualidade e na quantidade de valor energético da silagem produzida.

Rosa et al. (2004) conduziram um trabalho de avaliação de variedades de milho para a produção de silagem, no qual foram testadas três variedades de milho. Característica altura das variedades variou entre 1,69 a 1,84m. Os autores relataram uma associação positiva encontrada nas médias das alturas das variedades, produção de matéria verde e produtividade de massa seca ensilável. Embora neste trabalho, não tenha sido avaliado produtividade de silagem, tal característica é altamente correlacionada com PMS, que por sua vez, também apresenta uma associação com $\mathrm{H}$. As variedades que apresentaram maiores estimativas de médias para $\mathrm{H}$ também $\mathrm{o}$ apresentaram para PMS.

Para característica $\mathrm{H}$, a variedade RIBER K 9105 apresentou maior estimativa de média, diferindo estatisticamente apenas das variedades AS 1777 PRO3 e DKB 177 PRO3, que apresentam estimativa de média inferiores. Em trabalho desenvolvido por Silva Neto et al. (2017), identificaram diferenças significativas para a $\mathrm{H}$, entres quinze variedades analisadas em seu trabalho, sendo que duas apresentaram menores estimativas de altura. Uma menor altura de plantas é uma desejável para as cultivares de milho, pois ela permite o maior número de indivíduos em uma população e maior eficiência na colheita mecânica, ao mesmo tempo em que reduz problemas relacionados ao acamamento de plantas (KAPPES, 2010).

Para a característica HPE, não foi detectada diferença significativa entre as variedades. A estimativa da média das cinco variedades para esta característica foi de $81,20 \mathrm{~cm}$. Segundo Castoldi (2011), esta é uma característica de relevância para o produtor uma vez que espigas próximas ao solo são normalmente perdidas no processo de colheita mecanizada, o que pode afetar diretamente produtividade das variedades. Por fim, essa característica pode ser potencialmente relevante quando a cultura é cultivada em solos excessivamente irregulares situação normalmente encontradas como, nos solos da região do estado de Minas Gerais e algumas áreas da região da Nova Alta Paulista, onde este estudo foi realizado. 
Beleze et al. (2003) conduziu um trabalho de avaliação de híbridos de milho, visando investigar diferentes características morfológicas e as suas correlações. Os autores encontraram uma correlação positiva entre o Dc e a produtividade de massa seca das plantas. Embora correlações não necessariamente impliquem em relação de causa e efeito, este não era o caso. No experimento, não foi encontrada diferença significativa na ANOVA para a característica Dc. Na Tabela 4 estão apresentadas as correlações fenotípicas para as características avaliadas. A maior correlação foi verificada entre as características $\operatorname{NE}$ e PMS $(0,65)$, seguida da correlação entre NE e PMS $(0,60)$.

Tabela 4: Correlações fenotípicas das variáveis avaliadas em cinco variedades de milho safrinha em consórcio com Urochloa ruziziensis cv. Ruziziensis, semeadas em SPD sob cobertura vegetal, na região da Alta Paulista.

\begin{tabular}{cccccc}
\hline & H & HPE & Dc & PMS & PG \\
\hline NE & 0,4937 & 0,1933 & 0,2525 & 0,6472 & 0,1933 \\
H & & 0,7177 & 0,3833 & 0,5990 & 0,4831 \\
HPE & & & 0,0051 & 0,3630 & 0,4398 \\
Dc & & & & 0,3589 & 0,3543 \\
PMS & & & & & 0,4338 \\
\hline
\end{tabular}

Fonte: Dados de pesquisa, 2019.

Conforme experimento realizado por Rosales (2007), a produtividade de massa seca de planta inteira e das partes (lâmina foliar, caule, bráctea e sabugo) foi influenciada pelo espaçamento, sendo a produtividade total da planta inteira maior no espaçamento de $0,45 \mathrm{~m}$, correspondendo a $27,68 \%$ a mais que no espaçamento de $0,90 \mathrm{~m}$.

Com relação à característica PG, as variedades RIBER K 9105 e RIBER K 9606 VIP 3 apresentaram as maiores médias numéricas de produtividade, embora, não tenha sido detectada significância na ANOVA. Possivelmente, isto se deva ao fato de as variedades serem cultivares melhorados, altamente produtivos para a safrinha, com valores de produtividade que variaram entre $93 \mathrm{e}$ 119 sacas de milho por hectare. A média geral para esta característica foi de aproximadamente $6102 \mathrm{~kg} \mathrm{ha}^{-1}$ ou 102 sacas por hectare. Resultado um pouco acima do esperado para a safra 2018/2019 que é de $5000 \mathrm{~kg} \mathrm{ha}^{-1}$, conforme estima a Companhia Nacional de Abastecimento (CONAB, 2018).

Por fim, para PMS, foi detectado efeito diferencial entre os cultivares. As variedades RIBER $\mathrm{K}$ 9105 e RIBER K 9606 VIP3 proporcionaram estimativas de PMS de $7602 \mathrm{~kg} \mathrm{ha}^{-1}$ e 7028 kg ha-1 respectivamente, sendo as maiores produtividades em comparação com as demais.

\section{CONCLUSÃO}

Entre as cinco variedades de milho de segunda safra analisadas, as variedades RIBER K 9105 e RIBER K 9606 VIP3 se destacaram por apresentarem características desejáveis de produtividade grãos e de produtividade de massa seca de forragem; devendo ser recomendado para os produtores da região da Nova Alta Paulista, sob as condições em que foi realizado o estudo. 


\section{REFERÊNCIAS BIBLIOGRÁFICAS}

ADAMS, G. A. Influência de diferentes tipos de plantas sobre a estrutura do solo em plantio direto. $2016.45 \mathrm{f}$. Trabalho de Conclusão de Curso (Graduação) - Universidade Federal da Fronteira Sul, Cerro Largo, 2016.

ALLEN, R. G. et al.; Crop evapotranspiration - Guidelines for computing crop water requirements - FAO Irrigation and drainage paper 56. FAO, Rome, v. 300, n. 9, p. D05109, 1998.

ALVAREZ, C. G. D.; VON PINHO, R. G.; BORGES, I. D. Avaliação de características agronômicas e de produção de forragem e grãos de milho em diferentes densidades de semeadura e espaçamentos entre linhas. Ciência e Agrotecnologia, v. 30, n. 3, p. 402-408, 2006.

BELEZE, J. R. F. et al. Avaliação de cinco híbridos de milho (Zea mays, L.) em diferentes estádios de maturação. 1. Produtividade, características morfológicas e correlações. Revista Brasileira de Zootecnia, v. 32, n. 3, p. 529-537, 2003.

BORTOLETI JR., A. A Importância do Plantio Direto e do Plantio Convencional e as suas Relações com o Manejo e Conservação do Solo. Revista Conexão Eletrônica. Três Lagoas, v. 12, n. 1, 2015.

CASTOLDI, G. et al. Sistemas de cultivo e uso de diferentes adubos na produção de silagem e grãos de milho. Acta Scientiarum. Agronomy, v. 33, n. 1, 2011.

Companhia Nacional de Abastecimento, CONAB. Monitoramento agrícola - Safra 2017/18. Acomp. safra bras. grãos, v. 5 Safra 2076/18 - Nono levantamento, Brasília, p. 1-178, 2018.

EMPRESA BRASILEIRA DE PESQUISA AGROPECUÁRIA - EMBRAPA. Aspectos econômicos da produção e utilização do milho. Sete Lagoas: Embrapa Milho e Sorgo, 2006. 12p. (Circular Técnica, 74).

FAGERIA, N. K.; BALIGAR, V. C.; JONES, C. A. Corn. In: FAGERIA, N. K.; BALIGAR, V. C.; JONES, C. A. (Eds.). Growth and mineral nutrition of field crops. 3. ed. Madison: Marcel Decker, p. 313-342. 2011.

GOMES, M. S. et al. Variabilidade genética em linhagens de milho nas características relacionadas com a produtividade de silagem. Pesquisa Agropecuária Brasileira, v. 39, n. 9, p. 879-885, 2004.

KAPPES, C. Desempenho de híbridos de milho em diferentes arranjos espaciais de plantas. 2010. 127f. Dissertação (Mestrado em Sistemas de Produção) - Curso de Pós-Graduação em Agronomia, Faculdade de Engenharia, Universidade Estadual Paulista, Ilha Solteira, 2010.

MARIZ, B. L. Desempenho de Cultivares de Milho de Baixo Custo de Sementes da Safrinha 2016. XIV Seminário Nacional Milho Safrinha, p. 364-369, 2017.

PEREIRA FILHO, I. A. et al. Sistemas de Produção. - Portal Embrapa, 2015.

PIMENTEL, Gomes F. Curso de estatística experimental. Nobel, 1990.

R Core Team (2019). R: A language and environment for statistical computing. R Foundation for Statistical Computing, Vienna, Austria. URL https://www.R-project.org/.

RAIJ, B. V.; CANTARELLA, H.; QUAGGIO, J. A.; FURLANI, A. M. C. Recomendações de adubação e calagem para o Estado de São Paulo. 2 ed. Campinas: Instituto Agronômico \& Fundação IAC, 1996. 285 p. (Boletim técnico, 100).

ROSA, J. R. P. et al. Avaliação do comportamento agronômico da planta e valor nutritivo da silagem de diferentes híbridos de milho (Zea mays, L.). Revista Brasileira de Zootecnia, v. 33, n. 2, p. 302-312, 2004.

ROSALES, L. A. Produtividade e valor nutritivo de híbridos de milho para silagem em função do espaçamento e da densidade de semeadura. Aleph, [s. I.], p. v, 32 f. : tabs., 2007. 
SANTOS, H. G.; JOCOMINE, P. K. T.; ANJOS, L. H. C.; OLIVEIRA, V. A.; LUMBREARAS, J. F.; COELHO, M. R.; ALMEIDA, J. A.; FILHO, J. C. A; OLIVEIRA, J. B; CUNHA, T. J. F. Sistema Brasileiro de Classificação de Solos. 5.ed. rev. ampli. Rio de Janeiro: Embrapa. 2018; 531p.

SILVA NETO, A. A. et al. Produtividade de variedades de milho safrinha na região de Dourados-MS. Portal Embrapa. [s.d.]. Disponível em: https://www.embrapa.br/busca-de-publicacoes/-/publicacao/1083851/produtividade-devariedades-de-milho-safrinha-na-regiao-de-dourados-ms. Acesso em: 17 maio. 2019.

VELJKOVIĆ, V. B.; Biberdžić, M. O.; Banković-Ilić, I. B.; Djalović, I. G.; Tasić, M. B.; Nježić, Z. B.; Stamenković, O. S. Biodiesel production from corn oil: A review. Renewable and Sustainable Energy Reviews, v. 91, p. 531-548, 2018. 